\title{
ASTROINFORMATICS
}

DOI:http://dx.doi.org/10.18524/1810-4215.2020.33.216403

\section{THE EMISSION-LINE DUSTY OBJECT IRAS 07080+0605, A LESS-EVOLVED EXAMPLE OF THE RED RECTANGLE}

\author{
S.A. Khokhlov ${ }^{1,2}$, A.S. Miroshnichenko ${ }^{2,3,4}$, S.V.Zharikov ${ }^{5,1}$, N. Manset $^{6}$,
} O.V.Zakhozhay ${ }^{7}$, I.O. Bilinskyi ${ }^{7,8}$, K.N. Grankin ${ }^{9}$, A.V. Kusakin ${ }^{4}$, C.T. Omarov ${ }^{4}$, R.I. Kokumbaeva ${ }^{4}$, I.V. Reva ${ }^{4}$, D. Korčáková ${ }^{10}$, I.A. Usenko ${ }^{11,12}$, A.K. Kuratova ${ }^{1}$

${ }^{1}$ Physical-Technical Faculty, Al-Farabi Kazakh National University, Almaty, Kazakhstan, skhokh88@gmail.com

2 Department of Physics and Astronomy, University of North Carolina at Greensboro, Greensboro, NC, USA, a_mirosh@uncg.edu

${ }^{3}$ Main Astronomical Observatory of the Russian Academy of Sciences, Saint-Petersburg, Russia

${ }^{4}$ Fesenkov Astrophysical Institute, Almaty, Kazakhstan, raushan.raushan@mail.ru

${ }^{5}$ Institute for Astronomy, Universidad Nacional Autónoma de México, Ensenada, Mexico, zhar@astro.unam.mx

${ }^{6}$ Canada-France-Hawaii Corporation, Kamuela, HI, USA, manset@cfht.hawaii.edu

7 Main Astronomical Observatory, National Academy of Sciences of Ukraine, Kyiv 03680, Ukraine, zakhozhay.olga@gmail.com

${ }^{8}$ Department of Astronomical Science, The Graduate University for Advanced Studies, Tokyo, Japan, illia.bilinskyi@grad.nao.ac.jp

${ }^{9}$ Crimean Astrophysical Observatory, Nauchnyj, Crimea, konstantin.grankin@craocrimea.ru

${ }^{10}$ Astronomical Institute of Charles University, Prague, Czech Republic, kor@sirrah.troja.mff.cuni.cz

11 Astronomical Observatory, Odessa National University, Odessa, Ukraine, igus99@ukr.net

${ }^{12}$ Mykolaiv Astronomical Observatory Research Institute, Mykolaiv, Ukraine

ABSTRACT. The all-sky survey conducted by the InfraRed Astronomical Satellite (IRAS) in the 1980's discovered many objects with infrared excesses whose nature has not been explored until recently. IRAS $07080+0605$ is one of those identified in the visual spectral range with an early-type star, which shows the $\mathrm{B}[\mathrm{e}]$ phenomenon. The object is puzzling, because it exhibits one of the strongest infrared excesses associated with a star of one of the lowest surface temperatures $(\sim 8500 \mathrm{~K})$ among objects with the $\mathrm{B}[\mathrm{e}]$ phenomenon, an apparent combination of spectral features of dwarfs and supergiants, and the absence of a surrounding optical nebula. Our photometric and spectroscopic study shows that the object's properties are similar to those of the famous Red Rectangle proto-planetary nebula. In this paper we describe our findings and hypotheses about the nature and evolutionary status of IRAS $07080+0605$.

Keywords: Stars: emission-line, Be - Stars: evolution - (Stars:) circumstellar matter - (Stars:) binaries: general
АНОТАЦЯ. Завдяки огляду всього неба, проведеному супутником IRAS у 80-ті роки, було виявлено багато об'єктів 3 інфрачервоними надлишками, чия природа не була досліджена до сьогодення. IRAS 07080+0605 - один з цих, що був ідентіфікований, у візуальному діапазоні спектру, як зоря раннього спектрального класу, що показує В[e] феномен. Цей об'єкт є загадковим, тому що він демонструє один з найсильнійших інфрачервоних надлишків, що ассоціюється 3 зорею 3 однією 3 найменьших ефективних температур ( 8500 K) серед об'єктів з В[е] феноменом, очевидною комбінацією спектральних особливостей карликів та надгигантів, та відсутністю навколишньої оптичної туманності. Наші фотометрічні та спектральні дослідження показують що властивості об'єкту є подібними до відомої протопланетної туманності "Червоний прямокутник". В цій роботі ми описуємо наші знахідки та гіпотези щодо природи та еволюційного статусу IRAS $07080+0605$. IRAS $07080+0605$ - це перший об'єкт групи FS CMa, 
який може представляти ранню стадію подвійних зірок після стадії АGB. Здається, ця подвійна менш розвинена, ніж "Червоний прямокутник", але вона може йти тим самим еволюційним шляхом. Якщо припустити, що супутник типу А показує мало доказів дефіциту вогнетривких елементів, IRAS $07080+0605$, ймовірно, також менш розвинений, ніж пилові подвійн після стадії AGB. Молодий вік об'єкта не підтверджується енергетичним балансом між спостережуваним болометричним потоком та інтегрованим ІЧ-надлишком , відсутністю сусідньої зореутворюючої області та швидким зменшенням ІЧ-потоку у напрямку довших хвиль, що виявляє відсутність холодного пилу, типового для зірок до стадії Головній Послідовності.

Ключові слова: Зірки: емісійна лінія, Ве - Зірки: еволюція - Зірки: навколозоряна речовина - Зірки: подвійні файли: загальне

\section{Introduction}

Excess of infrared (IR) radiation in the spectral energy distribution (SED) of a star or stellar system typically manifests the presence of a circumstellar material in the form of gas and/or dust. Various distributions of this material produce different features in the object's spectrum, such as emission lines (both permitted and forbidden) that form in its gaseous part and emission or absorption bands that form in its dusty parts. Examples of these effects in the observational behavior of early-type stars are known as the Be phenomenon and $\mathrm{B}[\mathrm{e}]$ phenomenon. In particular, the B[e] phenomenon discovered by Allen \& Swings (1976) is defined as the presence of line emission (e.g., H I, Fe II, [O I]) and large IR excesses produced by circumstellar dust in the spectra of B-type stars. It has been detected in objects, which belong to five stellar groups: pre-main-sequence stars, symbiotic binaries, compact Proto-Planetary Nebulae, some supergiants, and FSCMa objects. The former four groups were identified by Lamers et al. (1998), while the latter one was proposed by Miroshnichenko (2007) to explain the properties of nearly half $(\sim 30)$ of the objects originally found by Allen \& Swings (1976) and called unidentified by Lamers et al. (1998).

The group of FS CMa objects exhibits the following observational features: a hot star continuum with emission lines of H I, Fe I, O I, [Fe II], [O I], Ca II; a large IR excess peaking at $\lambda=10-30 \mu \mathrm{m}$ and sharply decreasing at longer wavelengths; location outside of star-forming regions. A hot star in them has a spectral type between $\mathrm{O} 9$ and A2 and a luminosity range of $\log \mathrm{L} / \mathrm{L}_{\odot}$ between $\sim 2.0$ and $\sim 4.5$. Spectra of some FSCMa objects contain absorption lines of neutral metals typical of cool stars (e.g., MWC 623, MWC 728), while several other group members show evidence for the presence of a very evolved compact or even a degenerate secondary component (e.g., CI Cam, AS 386, 3 Pup). The main hypothesis about the nature of the FS CMa group implies that it comprises mostly intermediate-mass binary systems at an evolutionary stage after mass-transfer between the stellar components (e.g., Miroshnichenko 2007). Mergers of some binaries with remaining circumstellar medium cannot be ruled out as well (e.g., de la Fuente et al. 2015).

This paper is devoted to a study of the IR source IRAS $07080+0605(V \sim 12.0 \mathrm{mag})$, which has one of the strongest IR excesses among the objects with the B[e] phenomenon. The star associated with IRAS $07080+0605$ was detected by Kohoutek \& Wehmeyer (1999) in a survey for stars with $\mathrm{H} \alpha$ emission and designated as HBHA 717-01. Miroshnichenko et al. (2007) included it in the FS CMa group and suggested a binary nature. However, neither Miroshnichenko et al. (2007) nor a recent study by Condori et al. (2019) found a direct evidence of a companion in their limited observations. Additionally, the latter authors suggested that IRAS $07080+0605$ is an A[e] star with an uncertain classification, such as either main-sequence or pre-main-sequence object.

\section{Observations}

Optical spectroscopic observations of IRAS $07080+0605$ were obtained with échelle spectrographs at the following telescopes: $3.6 \mathrm{~m}$ Canada-France-Hawaii Telescope (CFHT, USA, spectral resolving power $R=\lambda / \Delta \lambda=65000), 2.7 \mathrm{~m}$ Harlan J. Smith telescope (McDonald Observatory, USA, $R=60000), 2.1 \mathrm{~m}$ telescope of the Observatorio Astronómico Nacional San Pedro Martir (OAN SPM, Mexico, $R=18000)$. One spectrum taken with the FEROS spectrograph $(R \sim 40,000)$ was retrieved from the ESO archive. Photometric observations were obtained with a $1 \mathrm{~m}$ telescope of the Tien-Shan Astronomical Observatory (Kazakhstan) in $B V R$ filters in 2014-2016. We have also used a $V$-band light curve from the ASAS SN all-sky survey (Kochanek et al. 2017).

\section{The properties of IRAS $07080+0605$}

The absorption-line spectrum of IRAS $07080+0605$ is represented by weak lines of He I, Fe II, Mg I as well as by strong hydrogen lines of the Balmer and Paschen series. Such a content is typical for early A-type stars. We found a good fit of the object's optical spectrum for $\mathrm{T}_{\text {eff }} \sim 8500 \mathrm{~K}, \log \mathrm{g}=3-4$, and a projected rotational velocity of $v \sin i \sim 60 \mathrm{~km} \mathrm{~s}^{-1}$ using the the program SPECTRUM (Gray \& Corbally 1994), which calculates synthetic spectra based on model atmospheres. At the 


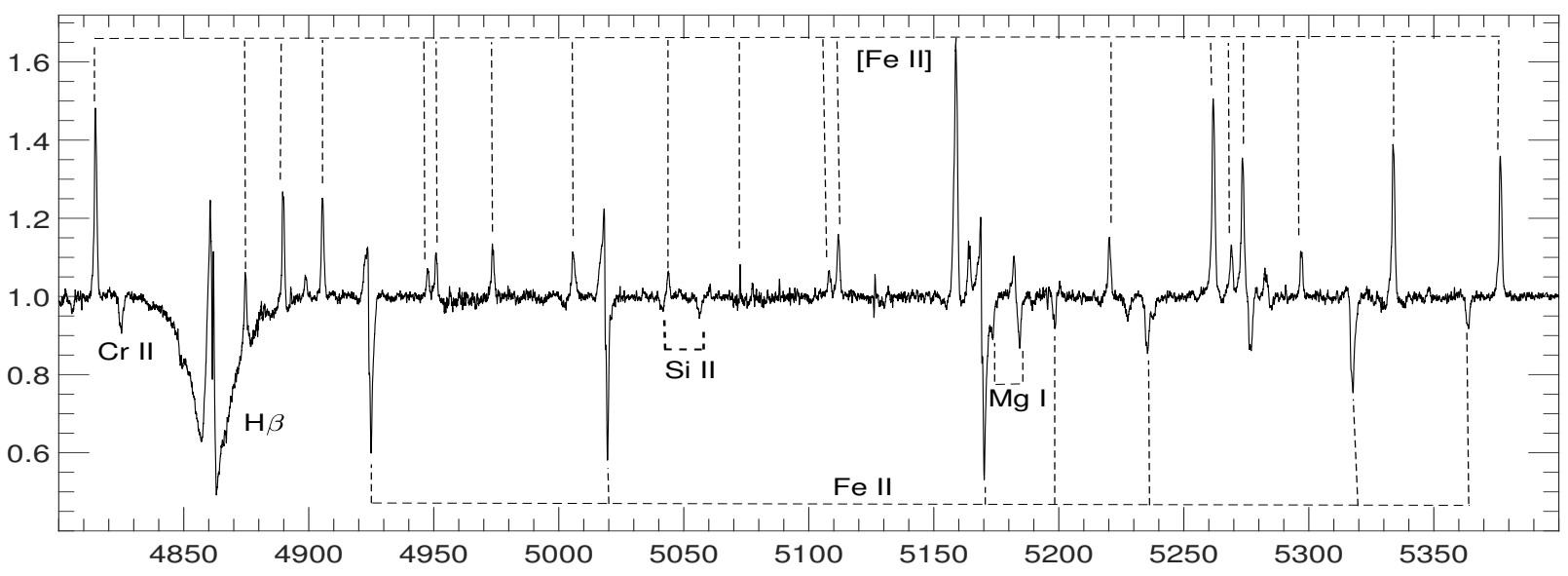

Figure 1: Part of the spectrum of IRAS $07080+0605$ taken at CFHT on 2018/11/20. Most identified spectral lines are shown with dashed vertical lines. Intensity is normalized to the local continuum, heliocentric wavelengths are shown in $\AA$.

same time, the O I $7772-7775 \AA$ triplet (equivalent width $\sim 3 \AA$ ) and Si II $6347 \& 6371 \AA$ lines (equivalent widths $\sim 0.3-0.5 \AA$ ), which are weak in the spectra of dwarf stars, are unexpectedly strong and comparable to those of the highest luminosity supergiants. The emission-line spectrum of IRAS $07080+0605$ includes emission components of the $\mathrm{H} \alpha$ and $\mathrm{H} \beta$ lines and forbidden lines of [O I], [Fe II], [Ca II], and [N II]. A part of the CFHT spectrum taken on 2018 November 20 is shown in Fig. 1.

Most emission lines in the spectrum of IRAS $07080+0605$ show variable profiles. In particular, the $\mathrm{H} \alpha$ line profile varies from a single-peaked to a triple-peaked (Fig. 2, top panel). Profiles of the forbidden oxygen lines $(6300$ and $6364 \AA)$ sometimes exhibit a strong central peak on top of a double-peaked structure typical of a circumstellar disk (Fig. 2, bottom panel).

The IR-excess of IRAS $07080+0605$ is unusually strong compared to the observed flux in the visual spectral region. Assuming that the object's brightness is affected by the interstellar extinction only, which is calculated from the color-excess $E(B-V)=0.1 \mathrm{mag}$, and using the effective temperature derived above, the bolometric flux from the star turns out to be $\sim 10$ times lower than the integrated IR-excess. The low interstellar extinction is supported by the absence of diffuse interstellar bands in the object's spectrum. This result implies that the star may be attenuated by almost grey circumstellar extinction and/or has a compact companion, which supplies additional energy to the circumstellar dust. The emission features detected in the IR spectrum of IRAS $07080+0605$ belong to carbonaceous molecules, which are typically observed in very evolved stars (e.g., planetary nebulae).

The parallax measured by the GAIA mission (GAIA Collaboration 2018) corresponds to a distance of
$543 \pm 15$ pc, which is consistent with the interstellar extinction law in the object's direction (Fig. 3) and the derived color-excess. Using the average optical brightness of IRAS $07080+0605(V \sim 12.0 \mathrm{mag}$, see Fig. 4) corrected for the interstellar extinction $\left(\mathrm{A}_{V}=3.1 \times E(B-V)=0.3 \mathrm{mag}\right)$ and the GAIA distance result in an absolute visual magnitude of $\mathrm{M}_{V}$ $=3.1 \mathrm{mag}$ and a luminosity of $5 \mathrm{~L}_{\odot}$, below the main sequence. It is difficult to reconcile some of the object's spectral features mentioned above (e.g., the oxygen triplet strength) and the strong IR excess with such a low luminosity. The absence of a nearby star forming region and a lack of the far-IR excess compared to that of pre-main-sequence stars contradicts the assumption of the object's young age made by Condori et al. (2019).

\section{Results and Discussion}

Positions of both the absorption and emission lines in the optical spectrum of IRAS $07080+0605$ are variable. In particular, the Si II absorption lines at 6347 and $6371 \AA$, which are nevertheless weak and noisy in some spectra, change their radial velocity determined by Gaussian fitting within $\pm 40 \mathrm{~km} \mathrm{~s}^{-1}$. The strongest Fe II lines (e.g., at 4923, 5018, $5169 \AA$ ) exhibit both absorption and emission components at their short-wavelength edge (see Fig. 1). This type of profile (inverse P Cyg) may be interpreted as evidence of the matter infall onto the A-type star.

Even a visual inspection of the light curve of IRAS $07080+0605$ composed from the data of the ASAS SN survey (Fig.4) implies the presence of a cyclic component in the brightness variations. Nevertheless, no stable period has been found in these data. After deleting a long-term trend, the most prominent period in the Fourier power spectrum is found at 127 

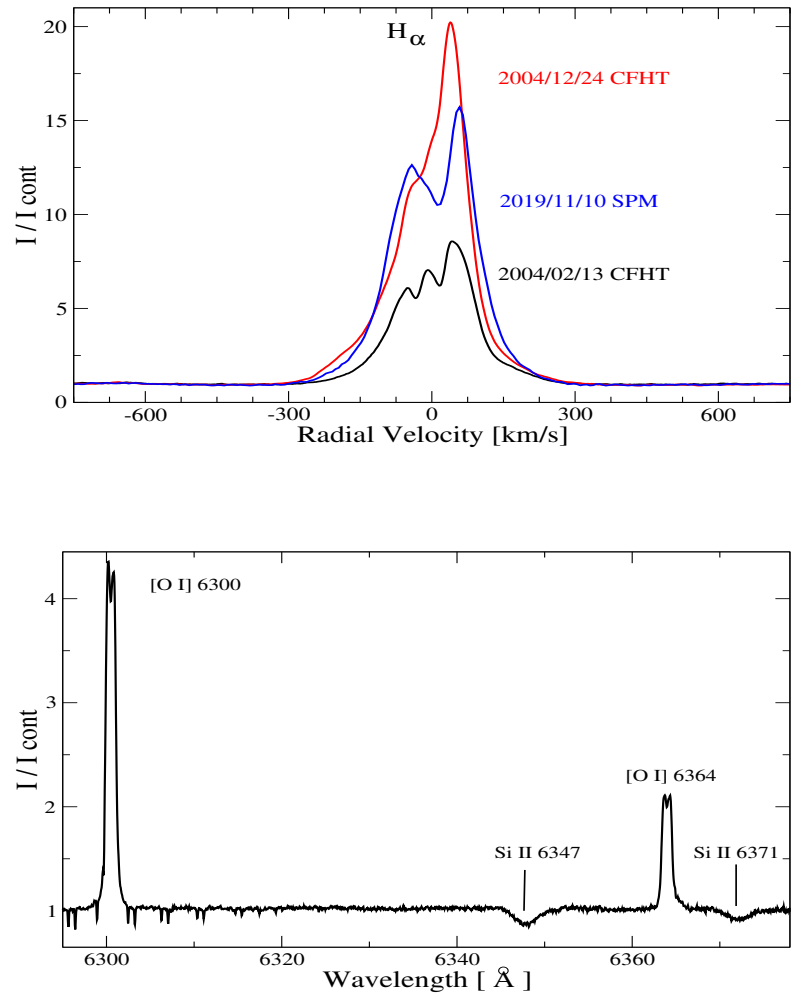

Figure 2: Top panel. Comparison of the $\mathrm{H} \alpha$ line profiles in the spectrum of IRAS $07080+0605$ taken at different times. Bottom panel. Part of the spectrum of IRAS $07080+0605$ taken at CFHT on 2018/11/20 with $[\mathrm{O}$ I] and Si II lines. Intensity and wavelengths are in the same units as in Fig. 1.

days, while the last three observing seasons suggest a period of 190 days. Condori et al. (2019) reported a most probable period of 72 days, although they also found that the highest peak in the Fourier power spectrum corresponds to 248.2 days based on the ASAS-3 survey data (Pojmanski 1997). The ASAS SN data do not show regular variations with these two periods.

The $B V R$ photometric data taken at TShAO shows no noticeable variations in the optical color-indices, although this data set is rather small (10 observations). Also, the high-resolution spectra taken near a local brightness maximum (ESO spectrum of 2015/12/06) and near a minimum (CFHT spectrum of 2018/11/20), time of whose taking is shown in Fig. 4) are nearly identical. Therefore, it is reasonable to assume that the cyclic variations are due to a variable circumstellar extinction rather than to eclipses in the system.

Among many objects with IR-excesses, there is one with a number of properties similar to those of IRAS $07080+0605$. This is HD 44179, a binary system with a brighter A/F-type post-AGB star and a much fainter hot companion. The system is surrounded by a prominent visual nebula known as Red Rectangle. Both the absorption-line optical spectrum and the IR

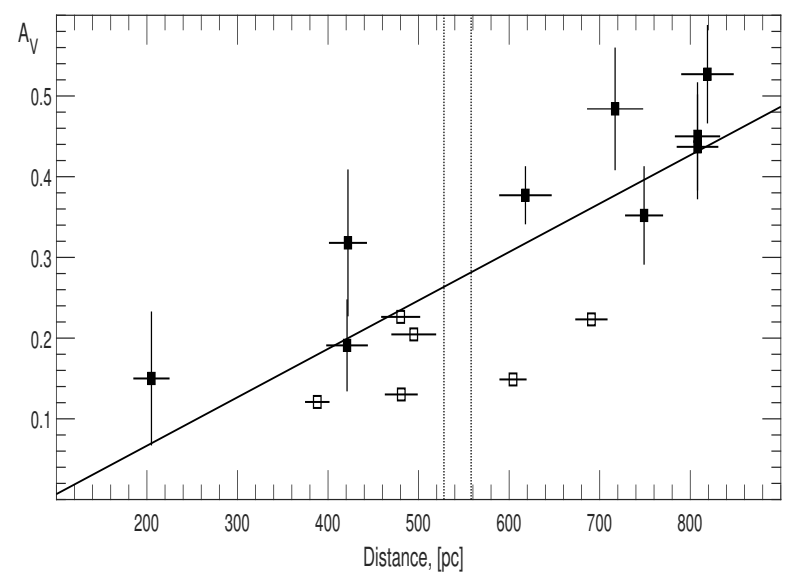

Figure 3: Interstellar extinction law in the direction of IRAS $07080+0605$. The thick line shows a linear fit to the star data, while the thin lines show the object's distance uncertainty. Filled and open symbols show data for stars from a 15-arcminute and a 1-degree area around the object, respectively.

spectrum resemble those of IRAS $07080+0605$ (Fig. 5).

The integrated flux in the IR excess of Red Rectangle is $\sim 18$ times larger than the bolometric flux of the bright stellar companion (Oomen et al.2019). Men'shchikov et al. (2002) modeled the SED of Red Rectangle and found that large carbonaceous grains in the circumstellar disk/torus attenuate the visible system component by a factor of $\sim 30$. A similar solution is probably applicable to IRAS $07080+0605$.

The largest difference between the two objects is that IRAS $07080+0605$ shows no detectable nebula around it, although both are located at about the same distance from the Sun $(0.5 \mathrm{kpc}$ for IRAS $07080+0605$ and $0.7 \mathrm{kpc}$ for Red Rectangle). Furthermore, IRAS $07080+0605$ shows somewhat wider absorption profiles of the Balmer lines (see Fig.5, top panel), which may imply a higher surface gravity than that of Red Rectangle ( $\log g=1.5$, Men'shchikov et al. 2002). If this is the case, IRAS $07080+0605$ is less evolved then Red Rectangle.

Visible components of most of the post-AGB binaries with dusty envelopes are cooler (FGK spectral type) than IRAS $07080+0605$ and demonstrate weaker absorption lines compared to those in the spectra of same spectral types with solar abundances. The latter effect has been explained by depletion of refractory elements from the star's atmosphere (Oomen et al. 2019). Although the absorption-line spectrum of IRAS $07080+0605$ resembles those of A-type dwarfs, it also contains some lines highly sensitive to the luminosity, such as the Si II 6347 and $6371 \AA$ lines and the O I triplet at 7772-7775 $\AA$ mentioned above, whose strengths are closer to those of giants and supergiants. This fact can be due to at least partial 


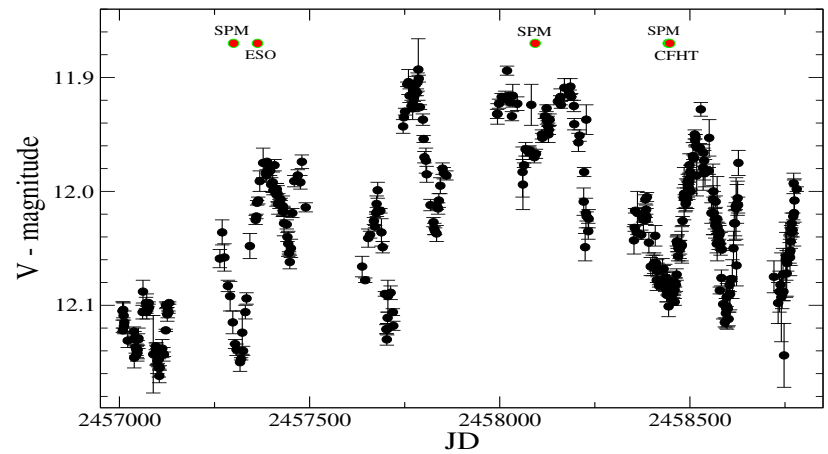

Figure 4: $V$-band light curve of IRAS 07080+0605 from the ASAS SN survey in 2013-2019 (Kochanek et al. 2017). Dates when some spectra of IRAS $07080+0605$ were taken at various observatories are shown above the light curve.

formation of these lines in the circumstellar area.

\section{Conclusions}

Our spectroscopic and photometric study of the FS CMa object candidate IRAS $07080+0605$ shows that in order to explain its observed properties one needs to assume that it is a binary system, in which:

1. the A-type companion's brightness is attenuated by the circumstellar disk-like envelope by a factor of 10 or more in order to explain the large amount of energy in the IR excess as Men'shchikov et al. (2002) did for Red Rectangle;

2. the secondary component is a hot star, which supplies UV photons to ionize the circumstellar gas;

3. some absorption lines, such as the Si II $6347 \&$ $6371 \AA$ and the near-IR oxygen triplet at $7772-$ $7775 \AA$ A, partially form in the circumstellar disk.

IRAS $07080+0605$ is the first object from the FS CMa group that may represent an early stage of binary post-AGB stars, which has been always studied separately (e.g., Van Winckel et al. 2009). The binary seems to be less evolved than Red Rectangle, but it may follow the same evolutionary path. Assuming that the A-type companion shows little evidence for the refractory element depletion, IRAS $07080+0605$ is probably also less evolved than the dusty post-AGB binaries. The young age of the object suggested by Condori et al. (2019) is not supported by the energy balance between the observed bolometric flux and the integrated IR excess, the absence of a nearby star-forming region, and a fast decrease of the mid-IR flux toward longer wavelengths which manifests a lack of the coldest dust typical for pre-main-sequence stars.
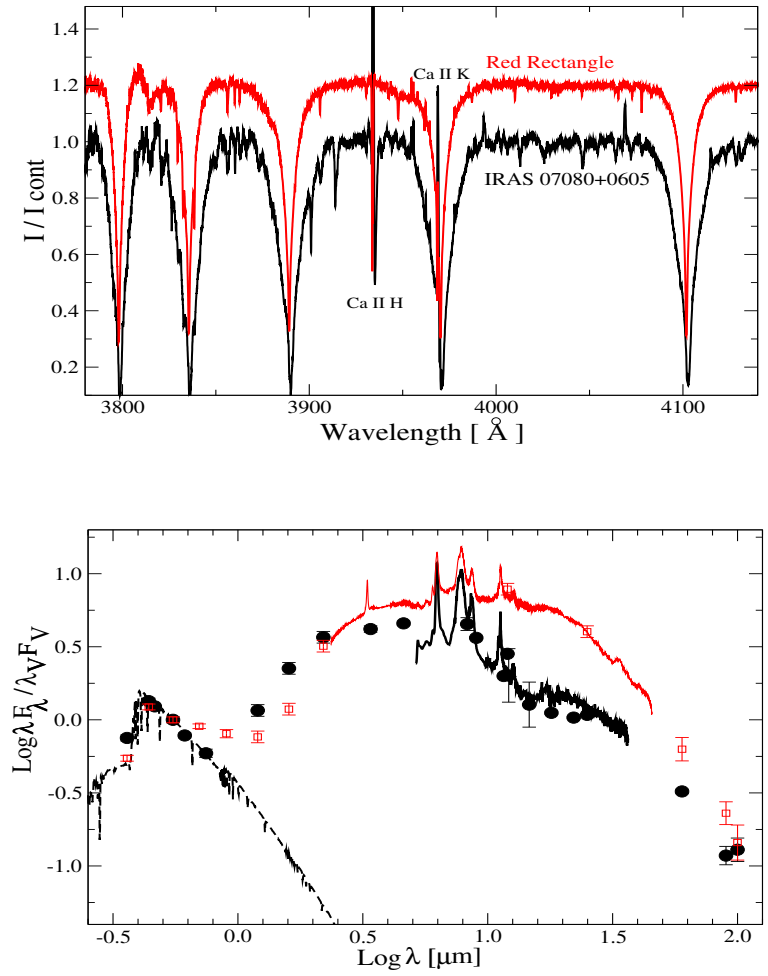

Figure 5: Top panel. Comparison of the blue part of the spectra of IRAS $07080+0605$ (black line) and Red Rectangle (red line) taken with the ESPaDoNs spectropolarimeter at CFHT. Bottom panel. Spectral Energy Distributions of IRAS 07080+0605 (black filled circles - photometric data, black solid line - IR spectrum taken at the Spitzer Space Observatory) and Red Rectangle (red open squares - photometric data, red solid line - IR spectrum taken at the Infrared Space Observatory) corrected for the interstellar reddening. The dashed line shows a theoretical SED for the model atmosphere for $\mathrm{T}_{\text {eff }}=8500 \mathrm{~K}, \log \mathrm{g}=3.0$. The same model atmosphere was chosen to show the IR excess, although the optically brighter component of Red Rectangle was found to be $\sim 800 \mathrm{~K}$ cooler (Waelkens et al. 1992). 
Acknowledgements. A. M. and S. Z. acknowledge support from DGAPA/PAPIIT Project IN102120. The work was carried out within the framework of the Project No BR05236322 "Studies of physical processes in extragalactic and galactic objects and their subsystems" funded by the Ministry of Education and Science of the Republic of Kazakhstan and by the Science Committee of the Ministry of Education and Science of the Republic of Kazakhstan (Grant No AP08856419). The results are partially based on observations obtained at the Canada-France-Hawaii Telescope (CFHT) which is operated by the National Research Council of Canada, the Institut National des Sciences de l'Univers of the Centre National de la Recherche Scientifique de France, and the University of Hawaii. The work of ZOV and BIO was partially conducted in frame of the budgetary program of the NAS of Ukraine "Support for the development of priority fields of scientific research" (CPCEL 6541230).

\section{References}

Allen, D.A., \& Swings, J.-P.: 1976, A\& A, 47, 293.

Condori, C.A.H., Borges Fernandes, M., Kraus, M., et al.: 2019, MNRAS, 488, 1090. de la Fuente, D., Najarro, F., Trombley, C., et al.: 2015, AधA, 575, A10.

GAIA Collaboration, Brown, A.G.A., Vallenari, A., et al.: 2018, A\&A 616, A1.

Gray, R.O., \& Corbally, C.J. 1994, AJ, 107, 742.

Kochanek, C.S., Shappee, B.J., Stanek, K.Z., et al.: 2017, PASP, 129, 104502.

Kohoutek, L., \& Wehmeyer, R.: 1999, A\&AS, 134, 255.

Lamers, H., Zickgraf, F.-J., de Winter, D., et al.: 1998, $A \mathscr{E A}, \mathbf{3 4 0}, 117$.

Men'shchikov, A.B., Schertl, D., Tuthill, P.G., et al.: 2002, A\&A, 393, 867.

Miroshnichenko, A.S.: 2007, ApJ, 667, 497.

Miroshnichenko, A.S., Manset, N., Kusakin, A.V., et al.: 2007, ApJ, 671, 828 .

Oomen, G.-M., Van Winckel, H., Pols, O., \& Nelemans,

G.: 2019, $A \mho A$, 620, A85.

Pojmanski, G.: 1997, Acta Astron., 52, 397.

Van Winckel, H., Lloyd Evans, T., Briquet, M., et al.: 2009, AछA, 505, 1221.

Waelkens, C., Van Winckel, H., Trams, N.R., \& Waters, L.B.F.M.: 1992, A\& A, 256, L15. 